\title{
Un modelo para la etnografía de interés público: la conjunción de teoría, práctica, acción y cambio en un mundo globalizado
}

\author{
A model for public interest ethnography: the conjunction of \\ theory, practice, action, and change in a globalizing world
}

\author{
Peggy Reeves SANDAY \\ Dept. of Anthropology \\ University of Pennsylvania \\ psanday@sas.upenn.edu
}

Recibido: 3 de marzo de 2013

Aceptado: 2 de julio de 2013

\begin{abstract}
Resumen
En este artículo se expone la historia de, y un modelo para, la Etnografía de Interés Público (EIP). El objetivo es codificar los medios por los que la teoría, la práctica y la acción para el cambio en un mundo globalizado pueden desarrollarse y han sido desarrolladas conjuntamente por etnógrafos que han adoptado un enfoque etnográfico micro aunque asociado también a consideraciones macro. El término "interés público" se refiere tanto a los intereses más amplios relacionados con el "bien común" (el nivel macro) como a los intereses específicos transmitidos por los actores en la esfera pública del debate y la acción en cualquier sociedad (el nivel micro). La participación en estos diversos niveles proyecta al etnógrafo dentro del terreno en el que conocimientos compartidos e intereses enfrentados compiten por la atención del público. El tema principal que subyace al objetivo de la EIP es unir la etnografía a la interpretación y al cambio en el dominio público.
\end{abstract}

Palabras clave: Interés Público; antropología sociocultural; etnografía; antropología comprometida; ciencia postmoderna comprometida; léxico para la etnografía de interés público.

\begin{abstract}
This paper outlines a model for and the history of Public Interest Ethnography (PIE). The aim is to codify the means by which theory, practice, and action for change in a globalizing world can and has been knitted together by ethnographers adopting a micro ethnographic approach wedded to macro considerations. The term "public interest" refers both to broader interests related to the "common good" (the macro level) and to specific interests aired by actors in the public sphere of debate and action in any society (the micro level.) Engagement at these various levels catapults the ethnographer into the realm of shared understandings and struggle as contested interests vie for public attention. The major theme underlying the goal of PIE is to join ethnography to interpretation and change in the public domain.
\end{abstract}

Keywords: Public Interest; sociocultural anthropology; ethnography; engaged anthropology; engaged postmodern science; lexicon for public interest ethnography. 
Referencia normalizada: Sanday, P.R. (2013) Un modelo para la etnografía de interés público: la conjunción de teoría, práctica, acción y cambio en un mundo globalizado, en Revista de Antropología Social, 22: 199-232.

SUMARIO: 1. Las fuerzas que mueven la historia: la antropología comprometida desde una perspectiva histórica. 2. Ciencia vs. Política. 3. La EIP y la ciencia: la ciencia postmoderna comprometida. 4. La etnografía comprometida por el cambio: algunos modelos de/para la EIP. 5. Consolidando un marco para la etnografía de interés público. 6. Algunas directrices conceptuales para la etnografía de interés público. 7. Conclusión. 8. Referencias bibliográficas.

Debemos hacer lo que nos corresponde en la tarea de apartar a la gente de su autosatisfecha rendición al prejuicio, y ayudarles a que puedan pensar de manera clara para que puedan entender los problemas a los que todos nos enfrentamos. (Franz Boas, Conferencia radiofónica, 1941).

Dado el poder de la humanidad tanto para alterar como para construir, y la dominación sobre ecosistemas que ella misma desestabiliza, su responsabilidad no puede ser sólo hacia sí misma sino que debe dirigirse hacia el mundo en su conjunto. Si la evolución, humana y de otro tipo, continúa, la humanidad debe pensar no sólo sobre el mundo, sino en nombre del mundo, del que es una parte muy especial y hacia el que, por tanto, tiene grandes responsabilidades. Si esto es cierto en un sentido general para la humanidad en su conjunto, es particularmente apremiante para aquellos, como los antropólogos, cuya profesión es pensar sobre estos asuntos. (Roy Rappaport, 1995:292)

Estos comentarios introductorios de reconocidos antropólogos norteamericanos marcan el comienzo y el final del siglo en el que la antropología sociocultural creció en relevancia dentro de la academia norteamericana y en la opinión pública. Antes del comienzo del siglo XX, la repercusión pública de la antropología consistía en informar al público sobre la "historia natural del hombre" en las exposiciones de los museos. Comenzando ya el siglo XX, el compromiso público de la antropología incluía un esfuerzo humanitario de parte de Franz Boas y sus estudiantes por informar sobre las diferencias culturales en otras sociedades. Boas dio conferencias radiofónicas y escribió para grandes audiencias. Ruth Benedict, una de sus estudiantes, publicó libros que consiguieron una amplia repercusión pública, al igual que Margaret Mead, otra estudiante que escribió también una columna en una revista popular.

La aproximación holística de Boas y sus estudiantes al estudio de las sociedades del mundo identificó una dimensión específicamente cultural de la vida humana, junto a sus componentes lingüísticos, arqueológicos o biológicos. Al hacerlo, plantearon las diferencias observadas transculturalmente en las costumbres humanas en términos de adaptación a las circunstancias ambientales e históricas, y destacaron la maleabilidad de la cultura frente a la pauta preconcebida de evolución cultural que marcó el pensamiento del siglo XIX. Esta aproximación desafió al etnocentrismo occidental, y fue crucial para la respuesta que dio Boas a las doctrinas racistas.

Con la expansión de la antropología dentro de la academia, se desarrolló una dicotomía que representaba la investigación antropológica como "pura" o "aplicada". 
Según transcurría el siglo, el humanismo de la tradición boasiana fue seguido, dentro como fuera de la academia, por antropólogos socioculturales que no se veían a sí mismos, sin embargo, dentro de ninguna tradición. Describían su trabajo recurriendo a diversas etiquetas que sugerían el compromiso público. Son ejemplos de ello la antropología-acción, formulada en la década de 1950; la antropología crítica, feminista, de interés público y práctica, formuladas como temas separados durante la década de 1970; la antropología militante, en 1992; la antropología comprometida, en 1995; y la antropología pública, en el 2000. En una encuesta bibliográfica realizada por oxford bibliographies ${ }^{1}$ mepeé la historia del compromiso público de la antropología norteamericana desde Boas hasta la actualidad y etiqueté estas perspectivas como "antropologías socioculturales públicas" (Sanday, 2012).

Hoy en día, hay dos perspectivas relevantes en la fusión de teoría, investigación y acción por parte de antropólogos socioculturales de orientación pública en los Estados Unidos, que abordan problemáticas humanas y se interesan por tendencias socioculturales en la propia o en otras sociedades. Una perspectiva interpreta el mundo a través de la lente de la investigación antropológica, con un ojo puesto en la dirección de estrategias correctivas a través de políticas y programas específicos; la otra está centrada en la construcción de una ciencia que desplaza su atención hacia los procesos públicos y globales mal ajustados o no equitativos, con el interés de desarrollar una ciencia socialmente responsable y sensible. Mientras que la primera perspectiva, de carácter más aplicado, une la investigación antropológica a los procesos políticos y a la educación en aras de un cambio inmediato, a menudo dirigido, la segunda busca expandir los marcos epistemológicos y conceptuales para el estudio de los procesos públicos sociales y culturales. Ambas perspectivas destacan y juzgan problemas contemporáneos con la mirada puesta en el cambio. De este modo, consideran su trabajo como algo distinto de la mera desvinculación científica de la investigación básica, usando para denominarlo los términos apuntados anteriormente.

Estos antropólogos socioculturales llegan al público desde muchos sitios, tanto dentro como fuera de la academia, online y de otras maneras, usando diversos medios de comunicación y populares outlets culturales. Hasta el momento, y por varias razones, hay poca unidad a la hora de plantear el cambio de paradigma, por varias razones, entre ellas está la tendencia de los académicos individuales a ser atraídos por la historia teórica y disciplinar en la que se formaron. El único punto común es el compromiso con lo local a la hora de hacer etnografía. Para que la antropología sociocultural como campo tenga impacto en el dominio público del siglo XXI, es necesario un enfoque relevante más identificable. Si la economía estudia el mercado, y si la ciencia política estudia la política - y ambas siguen siendo relevantes en las polémicas de la esfera nacional y global actual-, sugiero que la antropología sociocultural pueda ser identificada, más que por su exclusivo interés en el estudio de la cultura, por su trabajo en nombre del mundo a través del diagnóstico de, y la respuesta a, las fuerzas ajustadas y mal ajustadas en la arena local y global.

${ }^{1}$ Véase: http://www.oxfordbibliographies.com 
En este artículo codifico en términos generales los medios por los que teoría, práctica y acción para el cambio pueden unirse y se han unido adoptando un enfoque etnográfico micro, asociado a consideraciones macro. Denomino a los métodos y conceptos asociados, Etnografía de Interés Público (EIP). Tal y como se emplea aquí, el término "interés público" se refiere tanto a los intereses más generales que pueden ser locales, nacionales o globales (el nivel macro de análisis) - como a los intereses específicos transmitidos por los actores en la esfera pública de debate y acción en cualquier sociedad (el nivel micro). El hecho de comprometerse a esos distintos niveles proyecta al etnógrafo dentro del ámbito de los conocimientos compartidos y de los intereses enfrentados que compiten por la atención del público.

Barth alude a la complejidad que tengo en mente cuando sugiere que los etnógrafos afrontan "la tarea de construir modelos que representan sistemas desordenados, sistemas en flujo, formas que son a la vez difusas y emergentes". Sobre la fricción en los modernos procesos socioculturales, dice:

"La diversidad de posiciones y la multiplicidad de puntos de vista amplía impresio-
nantemente el campo de la contienda: nos enfrentamos no sólo con diferencias de
intereses, y con la lucha y la negociación que generan; debemos también reconocer
que esos contendientes están construyendo diferentes interpretaciones del mundo
y de los actos de cada uno de los otros, y así se articulan de manera singular y a
menudo débil con cada uno de los demás en sus enfrentamientos" (2000:151)

Cuando escribió esto, Barth era totalmente consciente de la "discusión teórica que queda por hacer antes de que sepamos lo que esto puede implicar y cómo se puede hacer" (ibídem). Lo que sigue ofrece más discusión sobre lo que esto podría implicar y cómo se refleja en algunas etnografías prototípicas.

Para la codificación de un marco EIP me baso en ejemplos de etnografía comprometida orientados hacia la acción. Los etnógrafos que se citan más abajo aportan ejemplos sobre dominios concretos de conflicto en el reconocimiento de la existencia de diferentes interpretaciones del mundo y de la disyunción entre el interés propio y los impactos más generales. Todos piensan en el cambio, diagnosticando y actuando respecto de los problemas a la luz de ideales universales o en relación con los impactos ambientales y/o de salud. Todos ven la cultura y la sociedad como flujo, aun estando atrapados en los habitus de los mundos culturales y las preocupaciones materiales de las tradiciones locales, incluso cuando se tejen nuevas redes de significación en respuesta al fermento del tiempo. Todos "entran en la lucha", según Tsing describe su participación en el movimiento ecologista en Kalimantan del que hablaremos más adelante.

Como antropóloga, entro en la lucha mezclando las particularidades de los datos con el desarrollo teórico, el análisis y la crítica cultural por el interés del cambio. Para mí, la preocupación con el cambio significa introducir diagnósticos e interpretaciones etnográficas dentro de la esfera pública de debate y acción, como hice al responder de manera etnográfica a los incidentes de abuso sexual de mujeres estudiantes llevados a cabo por grupos [gang banged] en varios campus universitarios de Estados Unidos. Trabajé a partir de mi investigación transcultural sobre 
"el contexto sociocultural de la violación" (Sanday, 1981) y de la etnografía de los campus. Desafié el entonces muy generalizado enfoque evolutivo de la sexualidad humana y la desigualdad sexual que se da en la violación por conocidos, con el fin de instigar la acción social en las universidades de Estados Unidos (Sanday, 2007; 2011). Mientras algunos antropólogos podrían llamar a lo que hice política cultural, otros podrían entenderlo como crítica cultural.

La crítica cultural se refiere al uso de la antropología para llamar críticamente la atención sobre "las asunciones que se dan por sentadas" sobre "cómo son las cosas". Criticar implica examinar los supuestos fundacionales de costumbres particulares en la propia sociedad, y comparar estos fundamentos con los que producen otras costumbres en otras sociedades. Es una práctica que se puede remontar a Boas y a aquellos de sus estudiantes preocupados por la educación del público. Por ejemplo, Ruth Benedict y Margaret Mead educaron al público sobre la variación cultural en todo el mundo, y rompieron nociones comunes sobre la relación entre naturaleza y cultura. Al escribir sobre la adolescencia en Samoa, Mead demostró que la adolescencia como periodo turbulento no era necesariamente el resultado natural del desarrollo sexual, como se suponía en los Estados Unidos. Unos años más tarde, George Marcus y Michael Fischer (1999) escribieron sobre el aparato conceptual desplegado al criticar la propia sociedad en referencia a referencia a otras sociedades.

El compromiso que empuja a la crítica cultural a entrar en la lucha en interés por el cambio plantea la cuestión de la ciencia frente a la política. Esta es una cuestión que persigue a la antropología cultural desde los inicios de la tradición boasiana por el compromiso y la crítica cultural. Examino esta historia más adelante, como preludio al surgimiento del debate sobre la ciencia frente a la política planteado por D’Andrade (1995) y Scheper-Hughes (1995). Replanteo esta problemática de cara al siglo XXI haciendo referencia a los parámetros de lo que Rappaport (1995), citando a Toulmin (1982), llama "ciencia postmoderna comprometida", en donde encaja el marco EIP.

Para sentar las bases del marco EIP destilo, por tanto, los puntos en común de varias etnografías relevantes. Sobre la base de un linaje de teóricos comprometidos y activistas sociales de la ciencia política, la sociología, la filosofía y la antropología, propongo un marco conceptual y un léxico para hacer etnografía de interés público. El tema principal que subyace a las diferentes fuentes en las que me baso es la intención expresada en la tesis número 11 sobre Feuerbach de Marx: "los filósofos no han hecho más que interpretar de diversos modos el mundo, pero de lo que se trata es de transformarlo". Empiezo con un poco de historia.

\section{Las fuerzas que mueven la historia: la antropología comprometida desde una perspectiva histórica}

En su "Filosofía de la Historia", Hegel argumenta que "pasión" y “deseo" están entre las fuerzas que mueven la historia. En el reto que Rappaport lanza a favor de un compromiso apasionado con el mundo, implícitamente sugiere que es hora ya de que la profesión antropológica se levante y tome su lugar como una de las fuerzas que mueven la historia. Al tratar de influir en el cambio ¿se convierte por ello la 
antropología en algo más que ciencia? Este tipo de cuestiones no preocupa a Hegel cuando afirma que "nada en absoluto se ha logrado nunca sin el interés activo de aquellos interesados en ello; y desde que el interés puede ser descrito como pasión... podemos decir sin ninguna reserva que nada grande se ha logrado en el mundo sin pasión" (Hegel, 1998:405;407).

Hegel se refiere a la pasión como "la energía del ego" o como "cualquier actividad humana que es gobernada por... intenciones egoístas". Como Parkinson (1989:291) explica, el uso que hace Hegel del término pasión no se refiere necesariamente a emociones de intensa ira o amor. En su filosofía de la historia, Hegel llama pasión "al brazo que sirve a la Idea" (ibid). Las "herramientas inconscientes y los órganos" del "espíritu del mundo" son actores apasionados en el escenario del mundo. En el curso de la historia, dice Hegel,

"Los intereses particulares compiten entre ellos, y algunos son destruidos en el proceso. Pero es a partir de este mismo conflicto y de la destrucción de lo particular desde donde emerge lo universal, y éste permanece indemne [...] Esto es lo que llamamos la astucia de la razón que hace que las pasiones trabajen a su servicio, como resultado de lo cual los agentes a través de los que se da existencia a sí misma deben pagar la pena y sufrir la pérdida" (Hegel, VG 105, N 89, traducción realizada por Nisbet; citado por Parkinson, 1989:291).

$\mathrm{Si}$, como el pensamiento de Hegel afirma, las pautas sociales no son destruidas sólo por fuerzas externas sino que son empujadas también por el peso de "contradicciones internas", entonces, para entender y para diagnosticar las contradicciones, los antropólogos deben entrar en la lucha por el cambio.

La historia inicial de la antropología practicada en los Estados Unidos estuvo marcada por una tradición de pasión social y compromiso público, que no sólo moldeó a la antropología sino que influyó igualmente en la cultura americana (ver Goldschmidt, 1979 y Stocking, 1966). Esto cambió a mitad de siglo, cuando la antropología sociocultural se retiró a la academia y se centró en las crónicas etnográficas de las sociedades y culturas del mundo, produciendo una gran abundancia de datos cribados a través de diversos marcos teóricos (ver Ortner, 1984 y 2006, para algunos de estos marcos). Fue sólo a finales del siglo XX cuando los antropólogos socioculturales volvieron a centrarse en la cuestión del compromiso, combinando el estudio de los asuntos públicos y el cambio en el paradigma de la antropología.

La historia inicial se refleja en el compromiso de Franz Boas con el otro exótico y con los asuntos sociales que se debatían en la esfera pública estadounidense. De este modo Boas transformó el concepto de cultura y la crítica cultural en la práctica etnográfica. Aunque muchas líneas de pensamiento en el siglo XIX dieron lugar al concepto de cultura, Stocking sostiene (1996:4) que Boas preparó el terreno institucionalmente y a través de sus estudiantes "para la emergencia de un concepto de cultura más 'antropológico' (i.e., plural, holístico, no jerárquico, relativista, determinista)".

Los primeros pensamientos de Boas sobre el significado de la cultura y su postura sobre la crítica cultural se desarrollaron a través de observaciones realizadas 
mientras hacía trabajo de campo entre los esquimales en 1883-84. Escribiendo a su prometida desde un iglú esquimal sobre la gente con la que estaba, aludió a dos de los principios centrales de su propio pensamiento: el poder determinante de la cultura y la importancia del relativismo cultural.

\begin{abstract}
"Cuanto más veo sus costumbres, más me doy cuenta de que no tenemos derecho a mirarles por encima del hombro. ¿Dónde entre nosotros podrías encontrar hospitalidad tan auténtica? Aquí, sin la más mínima queja, la gente está dispuesta a realizar cualquier tarea que se les pida... El miedo a la tradición y a las costumbres antiguas está profundamente implantado en la humanidad, y del mismo modo en que regula la vida aquí detiene todo progreso para nosotros. Creo que es una prueba difícil para todo individuo y para todo pueblo renunciar a la tradición y seguir el camino de la verdad... Como intelectual, para mí el resultado más importante de este viaje tiene que ver con el refuerzo de mi opinión de que la idea de una persona "cultivada" es meramente relativa. Todo lo que el hombre puede hacer por la humanidad es impulsar la verdad, ya sea dulce o amarga. Sólo este hombre puede decir en verdad que no ha vivido en vano" (citado por Stocking, 1968:148).
\end{abstract}

Boas también llevó a su experiencia en Tierra de Baffin un compromiso intelectual y personal con los ideales sociales universales. En otra efusiva entrada de su diario dirigida a su prometida, escribió: “¡Por lo que quiero vivir y morir es por la igualdad de derechos para todos, igualdad de posibilidades de aprender y trabajar para pobres y ricos por igual! ¿No crees que haber hecho incluso lo mínimo por esta causa es más que toda la ciencia tomada en su conjunto?" (24 de Enero de 1884; citado por Cole 1983:37). Esta declaración es llamativa por su compromiso temprano con el ideal de la igualdad racial que motivó a Boas en sus últimas investigaciones, escritos y declaraciones.

Se aprecia este compromiso en el debate que mantuvo Boas con la "etnología evolutiva" tal y como aparece en el trabajo de su contemporáneo Daniel Brinton, y que prevalecía en la cultura popular estadounidense (ver Baker, 1998). Boas estaba en desacuerdo con las discusiones públicas que tenían lugar en los Estados Unidos sobre la "herencia racial" y los atributos mentales, y defendía el poder determinante de la tradición y la costumbre. Aunque fueron sus estudiantes los responsables de la elaboración del concepto de cultura, la afirmación de Boas de que es la cultura, y no la raza ni la evolución, la base de la diversidad humana, desafió al pensamiento norteamericano sobre la raza como categoría científica. Aunque no consiguió la abolición de la discriminación racial, proporcionó el marco que debilitó su fundamento intelectual. De este modo, introdujo la ciencia de la cultura en la corriente del debate histórico. Hasta hoy, el marco boasiano compite con el racismo y el esencialismo de los tiempos modernos en su habilidad para conformar la opinión pública, el pensamiento social y la política legal (ver la discusión en Stocking, 1968:231; 223; y más recientemente Handler, 1998:458).

Boas fue ambivalente respecto de la relación entre ciencia y compromiso público. Esa ambivalencia se expresó en su alocución radiofónica difundida en 1941 
(ver epígrafe), el año antes de que muriera, en la que aconsejaba a sus "compañeros científicos" que sacrificaran el compromiso público en interés de la ciencia:

\begin{abstract}
"No podemos renunciar a nuestro trabajo como científicos sin causar un daño irreparable a nuestra cultura, por alejado que pueda estar nuestro tema de las necesidades urgentes y prácticas de nuestro tiempo. La llama helada de la pasión por buscar la verdad por la verdad debe seguir ardiendo, y sólo puede mantenerse viva si continuamos buscando la verdad por la verdad" (Boas, 1945:1).
\end{abstract}

Cambiando de dirección, Boas continuó el discurso diciendo que la búsqueda de la verdad no podía seguir siendo únicamente un "privilegio de los científicos". Nos estamos enfrentando a un "nuevo deber", decía. "Debemos hacer lo que nos corresponde en la tarea de apartar a la gente de su autosatisfecha rendición al prejuicio, y ayudarles a que puedan pensar de manera clara para que puedan entender los problemas a los que todos nos enfrentamos." Pensar de manera clara en este caso significa pensar más allá de los grilletes del "saber tradicional", y ser apartados de la "tiranía de la costumbre" para "reconocer los prejuicios" y "respetar la verdad por la verdad" (Boas, 1945:1-2).

Situando la verdad tanto en la ciencia de la cultura como en los "problemas a los que todos nos enfrentamos", Boas cae en una contradicción. Si la ciencia significa falta de compromiso con "las necesidades urgentes y prácticas de nuestro tiempo", la idea de apartar a la gente del prejuicio significa justamente lo contrario. Rabinow $(1983: 68,70)$ reconoce la inconsistencia, cuando señala que Boas fue un "hombre profundamente político" que separó verdad y poder con el fin de "hablar de la verdad al poder, centrando la verdad en los prejuicios" y, yo añadiría, separando así las verdades del "pensamiento claro" de la pasión del prejuicio.

Según Ruth Brunzel, con estos planteamientos Boas demuestra su creencia de que "el hombre era un animal racional y podía mediante su persistente esfuerzo, emanciparse de la superstición y la irracionalidad". Este aspecto refleja la noción de Hegel de que es a través de "la astucia de la razón" como los humanos piensan en el curso de la historia y lo cambian. El énfasis de Boas en el poder de la cultura cambió el curso de la historia. Brunzel puntualiza que su "objeto fue la iluminación de la humanidad a través de [la racionalidad de] la antropología" (Brunzel, 1962:6). Bajo mi punto de vista, éste es un planteamiento temprano de la necesidad de moverse más allá del relativismo cultural para insertar en los argumentos antropológicos principios universales, a los que Rappaport se refiere como "formulaciones macroantropológicas".

Las referencias de Boas a "apartar a la gente de los prejuicios" y a inculcar "el poder del pensamiento claro" son una reminiscencia del desarrollo de la teoría crítica de la escuela de Frankfurt en la década de 1930, basada en el pensamiento hegeliano y marxista. En 1937, Horkheimer describió los principios básicos de la teoría crítica, diciendo que tenía "por objeto a los hombres en tanto que productores de todas sus formas históricas de vida". De acuerdo a los planteamientos de Horkheimer, la teoría crítica "no es sólo una hipótesis de investigación que muestra su valor en los negocios en marcha de los hombres; es un elemento esencial en el 
esfuerzo histórico y en los poderes de los hombres... Su objetivo es la emancipación del hombre de las relaciones que le esclavizan" (citado por Benhabib, 1986:3).

La teoría crítica puede distinguirse de la teoría "tradicional" por su énfasis en explicar y transformar "todas las circunstancias que esclavizan a los seres humanos". Por ejemplo, durante el siglo XX, las teorías críticas emergieron en conexión con movimientos sociales, identificando las diversas dimensiones de la "dominación de los seres humanos en las sociedades modernas" para identificar las bases descriptivas y normativas tendentes a "la disminución de la dominación y al incremento de la libertad" (Bohman, 2005:s/p).

Las ideas de Boas a finales del siglo XIX y principios del XX prefiguran las de Pierre Bourdieu a finales del siglo XX cuando defendió el estudio de los "intereses públicos". Se puede comparar la opinión de Boas (1945:1-2) sobre la necesidad "de apartar a la gente de su autosatisfecha rendición al prejuicio", con las ideas de Bourdieu sobre la necesidad de hacerlo en interés del cambio. Aunque normalmente no es identificado como un teórico crítico, en la última década de su vida Bourdieu estuvo abierto a un compromiso con "lo público" y "el interés público". Cuando escribía y hablaba sobre "el interés público", usaba libremente conceptos como "bien público", "interés colectivo", "responsabilidad colectiva" y "virtud cívica" (Bourdieu, 1998a:4-7). Es devastador en su ataque a intelectuales y políticos que "son terriblemente cortos de ideales que puedan movilizar a la gente" (ibid., p.5).

En lugar de la "tiranía de la costumbre" de Boas, Bourdieu habla de los "campos sociales" que "exige el mundo". Dice que "a menudo queda aturdido por el grado en el que están determinadas las cosas". "Créeme, dice, no me alegro de esto" (Bourdieu y Wacquant, 1992:19-20). Más adelante en su carrera, Bourdieu llegó a la conclusión de que la ciencia social puede ser un camino hacia la libertad. Lo que él llama "sociología reflexiva" abre "la posibilidad de identificar verdaderos lugares de libertad y, por lo tanto, de construir a pequeña escala modestas morales prácticas acordes con los límites de la libertad humana", por estrechos que puedan ser. La sociología reflexiva enseña a la gente a "conocer un poco mejor qué son y qué hacen", ofreciéndole los medios para pensar sobre sí misma (Bourdieu y Wacquant, 1992:198). Estas palabras son sorprendentemente parecidas a las de la petición que hizo Boas en 1941 de una antropología que enseñara "el hábito del pensamiento claro", para que, de ese modo, la gente pudiera desarrollar una comprensión más racional de sí misma y de los otros (Boas, 1945:1-2).

La solución de Bourdieu hace hincapié en inculcar el arte de la reflexividad a través de la sociología. Haciendo referencia al tema del compromiso, afirma:

"Yo creo que cuando la sociología permanece en un nivel muy formal y abstracto, no sirve para nada. Cuando desciende a los aspectos esenciales de la vida real, es un instrumento que la gente puede aplicarse a sí misma con propósitos cuasi-clínicos. La verdadera libertad que ofrece la sociología es darnos una pequeña oportunidad de conocer el juego al que jugamos y de minimizar los modos como somos manipulados por las fuerzas del campo en el que nos desenvolvemos, así como por las fuerzas sociales incorporadas que operan desde dentro de nosotros. No estoy sugiriendo que la sociología resuelva todos los problemas del mundo, en absoluto, 
pero nos permite discernir los lugares donde disfrutamos realmente de un grado de libertad y aquellos en los que no lo hacemos. De manera que no gastemos energías luchando en terrenos que no nos ofrecen libertad de acción" (Bourdieu y Wacquant, 1992:198-99).

Ruth Benedict, Margaret Mead y Sol Tax, entre otros, continuaron el legado boasiano expandiendo la reputación de la antropología como ciencia de la cultura y comunicando a la opinión pública el rol de la cultura en la vida diaria. Benedict y Mead escribieron sobre el determinante poder de la cultura en diversas sociedades: Benedict sobre la relación entre tipos de personalidad y pautas de cultura; Mead sobre la adolescencia y pautas de género en el comportamiento social. A través de su trabajo con los nativos americanos y sus proyectos en Chicago, Tax (1988) (Stocking, 2000) cuestionó la opinión estadounidense sobre la asimilación, introduciendo el valor de la diferencia cultural y el pluralismo.

La pasión social que motivó a esos primeros antropólogos a hablar sobre ciencia y sociedad inspiró mis primeros pensamientos sobre una antropología de/para el interés público, como lo hizo también el desafío lanzado por Dell Hymes (1969) en su libro Reinventing Anthropology. En la introducción, Hymes (1969:7) enumera las disposiciones fundamentales que motivan el compromiso inicial de la antropología: "sensibilidad, conciencia crítica, preocupación ética, relevancia humana [y establecer] una clara conexión entre lo que hay que hacer y los intereses de la humanidad". En un tiempo en el que prevalecía el cientificismo, la atrevida iniciativa de Hymes permaneció aislada durante años. Su desafío fue repetido más tarde en el llamamiento que hizo Rappaport (1995:292) por una "antropología comprometida" como "único medio que el mundo tiene para pensar sobre sí mismo". Rappaport desempeñó un importante papel en el resurgimiento de esta conciencia en la década de 1990, como presidente de la Asociación Americana de Antropología (AAA). Creó el Comité sobre Problemas de las Sociedades Industriales (Forman, 1995), y desempeñó un papel en el libro editado por Moran (1996) sobre la transformación de la antropología. James Peacock y Yolanda Moses, los presidentes de la AAA en este periodo, tomaron también el testigo. Peacock $(1995 ; 1997 ; 1999)$ trazó su visión del "futuro de la antropología". Moses es bien conocida por su iniciativa pública sobre la raza (1999; ver también Goodman et al., 2012). Estos y otros desarrollos mostraron un resurgimiento con renovada energía del compromiso boasiano.

Para aquellos de nosotros que habíamos estado trabajando desde el principio como antropólogos comprometidos, el cambio fue bien recibido. Aunque había estado involucrada en cuestiones de interés público desde los comienzos de la década de 1970, editando un libro titulado Anthropology and the Public Interest en 1976, no encontré audiencia para mis propuestas hasta mediados de la década de 1990. En un seminario de la Universidad de Pensilvania en 1997, Francis Johnston, Julia Paley, Paula Sabloff y yo nos reunimos para desarrollar un programa de investigación, formación y acción en el dominio público. Durante ese tiempo, llamábamos al programa que teníamos en mente "antropología de interés público", en parte debido al primer libro que había editado, pero intentando impulsar el esfuerzo hacia 
el siglo $\mathrm{XXI}^{2}$. El siguiente año organizamos una sesión de la AAA en Philadelphia con el nombre "Definiendo una Antropología de Interés Público". El nuestro no fue el único esfuerzo que se estaba realizando en esta línea. Al mismo tiempo, Roberto Borofsky (2000) creó una colección de libros sobre "antropología pública".

Muchos otros esfuerzos vieron la luz con el cambio de siglo, demostrando un movimiento hacia la etnografía de los problemas sociales. Por ejemplo, la etnografía de Lutz (2001) sobre una comunidad militar examinaba el significado y el impacto del militarismo en los Estados Unidos; la etnografía de Sanjek (1998) en su comunidad urbana de Nueva York, destacó el impacto de la acción comunitaria para el cambio local; y Paley (2001) demostró cómo los llamados procesos democráticos que se vienen realizando en Chile confunden el funcionamiento de los privilegios y los intereses económicos. Estas etnografías interpretan el mundo en interés del cambio, y sus autores entran en la lucha del cambio por su compromiso con los públicos locales y a través de sus apariciones públicas.

La tensión entre ciencia y política se pone de manifiesto durante este periodo en el debate entre Nancy Scheper-Hughes y Roy D'Andrade, publicado en Current Anthropology en 1995, más de medio siglo después de la alocución radiofónica de Boas en 1941. La respuesta de Scheper-Hughes a D'Andrade pudo haber supuesto el golpe final al compromiso de la antropología académica con la definición tradicional de ciencia. Sus argumentos son interesantes para entender la definición posterior de ciencia que Rappaport (1995) propone para la antropología.

\section{Ciencia vs. política}

D'Andrade (1995:399) hace una apasionada defensa de la antropología basada en un "modelo objetivo" en lugar de "un modelo moral del mundo". Caracteriza un "modelo objetivo" como el "que intenta describir el objeto" en busca de "verdades empíricas sobre el mundo" (1995:400; 402). Afirma que "la intención de un modelo moral es identificar qué es bueno y malo para repartir alabanzas y culpas" Dejando la agencia humana fuera de su modelo "objetivo" y poniendo el énfasis en las "verdades empíricas" de aquí y ahora, D'Andrade evita el uso de la antropología para dirigirse a la gente y reforzar un "pensamiento claro" frente a tendencias desajustadas. Su hincapié en las verdades empíricas asume una visión estática de las formas culturales y la acción humana, sin dejar espacio para el flujo, el movimiento y el cambio.

Scheper-Hughes (1995:409) hace una defensa del compromiso moral y político afirmando que para que la antropología "sirva de algo, debe tener unas bases éticas". Declara que el "relativismo cultural", que ella etiqueta como "relativismo moral", "ya no es apropiado para el mundo en el que vivimos", devastado por la pobreza, el hambre y la violencia. Argumentando a favor de una antropología éticamente fundamentada, Scheper-Hughes (1995:410) llama a usar la antropología para la ilustración, imaginando "qué formas podría tomar una antropología comprometida política

${ }^{2}$ Para un resumen de las conclusiones de ese seminario, véase http://www.sas.upenn. $\mathrm{edu} / \sim$ psanday/public2.html 
y moralmente". Sugiere que la antropología podría utilizarse para ayudar a la gente a encontrar las respuestas a, y la comprensión de, asuntos de vida y muerte. En el contexto de su compromiso etnográfico con la enfermedad, el hambre y la muerte en el nordeste de Brasil, Scheper-Hughes (1995:410-411) localiza la verdad en la tragedia del hambre y en las luchas diarias por sobrevivir, no en los resultados de una investigación des-implicada. Su compromiso es un esfuerzo por entender para ayudar, igual que un investigador médico frente a la epidemia intenta comprender sus causas con el fin de encontrar una cura.

Se pueden mencionar otros enfoques que tratan la problemática ciencia/política. Por ejemplo, mi primera investigación sobre las 'violaciones sexuales en grupo dentro de las fraternidades' en los campus de los Estados Unidos (Sanday, 2007) localiza la verdad en el trauma de mujeres jóvenes que son víctimas de sexo en grupo sin consentimiento (por ingesta de alcohol), un trauma agravado por la tibia respuesta de los administradores universitarios cuando les comunican su experiencia. Subiendo en la escala de la abstracción, cuestioné el ideal de igualdad de género en campus donde las mujeres estudiantes se convierten en presa sexual en las fiestas de los colegios mayores universitarios. Mi argumentación se basaba en una investigación transcultural realizada a finales de la década de 1970 y publicada en 1981. Desarrollando una explicación coherente del contexto socio-cultural de la violación en una muestra de sociedades tribales (Sanday, 1981), que demostró que la violación estaba altamente correlacionada con variables socioculturales relacionadas con la guerra y la dominación social masculina, desmonté la opinión popular de que la violación masculina no tenía una base cultural. Al dirigirme con mis escritos a las audiencias de las universidades mi objetivo era reformar la opinión estadounidense sobre la violación por conocidos (ver también Sanday, 2011).

D'Andrade etiquetaría mi modelo como moral, y lo definiría como política cultural. Estoy de acuerdo, pero añadiría que entré en el ámbito público como una científica moralmente comprometida, que apoyó su caso en la interpretación de "verdades empíricas" a la luz de prejuicios basados en el sexismo. La principal diferencia que me separa de D'Andrade es que mi objetivo final no es "la verdad por la verdad". Al igual que Scheper-Hughes, mi objetivo es usar la antropología para, como Boas (1945:2) dijo en la segunda parte de su conferencia radiofónica, "entender los problemas a los que todos nos enfrentamos". Clasifico mi trabajo como ciencia, pero no encaja en la visión ideal de ciencia que Boas enunció en la primera parte de su discurso y que D'Andrade defiende. Más bien, encaja con la lógica científica más flexible de la antropología comprometida, que (1995:289-290) llama "ciencia postmoderna comprometida".

\section{La EIP y la ciencia: la ciencia postmoderna comprometida}

Tal y como fue concebida por Toulmin (1982), la ciencia postmoderna no se refiere al "postmodernismo" de finales del siglo XX, sino que se presenta como una alternativa al distanciamiento de la "ciencia moderna". Rappaport señala que el compromiso apasionado con los problemas no excluye "su análisis desapasionado". Adaptando las ideas de Toulmin a la antropología, Rappaport defiende la 
vinculación de la ciencia y la acción y se implica "en los problemas del mundo — pobreza, hambre, degradación ecológica, desigualdad, racismo, opresión-y sus causas subyacentes", a fin de desarrollar soluciones que denomina "teorías de corrección". Dado que el compromiso de la "ciencia postmoderna" no está "libre de valores", Rappaport dice que "ha de ser sincera sobre su dimensión valorativa". La dimensión valorativa se refleja en lo que denomina (1995:285) la "formulación macroantropológica" que descansa en la "investigación micro". Esta última se refiere a la práctica etnográfica y otros métodos de estudio de los fenómenos locales; la primera, remite a la formulación de evaluaciones más abstractas sobre las tendencias ajustadas o desajustadas. De acuerdo con Rappaport (1995:282), uno reconoce las formas de desajuste ("desórdenes estructurales que subyacen a los síntomas") a través del proceso diagnóstico.

Un ejemplo de diagnosis de desórdenes nos lo ofrece la discusión de Rappaport sobre el principio de "contingencia" (Rappaport, 1995:266). Se produce un tipo común de desorden cuando la relación de contingencia se invierte, de manera que los valores últimos relacionados, por ejemplo, con la protección del medio ambiente, se convierten en contingentes respecto de valores económicos. La alteración del orden de los valores violando el principio de contingencia, colocando, por ejemplo, los valores económicos por delante de las necesidades biológicas y ecológicas, produce desórdenes tanto sociales como ecológicos. Rappaport (1995:284-286) sugiere que, dado que es posible conceptualizar los desórdenes de acuerdo a ciertos principios, podemos también desarrollar una “"teoría de la corrección” antropológica" y “"antropologizar' la comprensión pública”. De acuerdo con Rappaport (1995:285), el desarrollo de modelos macroantropológicos que proporcionen estándares para el diagnóstico de desórdenes es crucial si la antropología quiere al menos ocupar su puesto en los "ámbitos que importan... comparable en alcance a los de la ciencia política o la economía". Rappaport justifica su planteamiento con la observación de que "la humanidad no se encuentra simplemente "suspendida en redes de significados' como Geertz (1993) planteó, sino que está atrapada entre significados que pueden ser malentendidos y leyes que pueden ser misterios" (Rappaport, 1995:287). Las leyes a las que se refiere son los procesos psíquicos y sociales más amplios, con los que los significados locales pueden estar relacionados, ya como causa o como efecto. Diagnosticar estos procesos está en el corazón del marco EIP, al que ahora volvemos.

\section{La etnografía comprometida por el cambio: algunos modelos de/para la EIP}

Para sentar las bases y proponer principios generales y estrategias de investigación, que "antropologicen" el conocimiento público y se impliquen en el juego de niveles micro y macro de cambio, examino los puntos en común de cuatro etnografías comprometidas. Tomadas según su orden de publicación, las etnografías consideradas son: Fraternity Gang Rape (Sanday, 2007); Death Without Weeping 
(Scheper-Hughes, 1992) ${ }^{3}$; Friction (Tsing, 2005); y Local Democracy Under Siege (Holland et.al., 2007). Aunque estas etnografías tienen diferentes marcos teóricos, estilos y objetos de estudio, todas reflejan el compromiso ético con asuntos sociales críticos; todas están motivadas por una pasión social por trabajar en favor de públicos particulares e ideales universales; todas exploran los intereses en torno a los que las personas se movilizan para la acción; todas inspiran reflexión sobre el cambio social; y todas se ocupan de cómo las personas encuentran un terreno común en el trabajo por objetivos sociales más amplios. Como tales, todas muestran las tareas complejas de la creatividad social humana. Todas se dirigen a múltiples públicos.

Fraternity Gang Rape. Mi etnografía sobre la cultura festiva en los campus universitarios surgió por una experiencia que una estudiante me relató en una de mis clases en 1983. Al regresar a clase después de haber estado ausente durante varias semanas, me explicó el motivo de su ausencia. Se remangó su jersey enseñándome cardenales en sus brazos y me dijo que la habían violado ["gang banged"] seis "hermanos" después de una fiesta en una fraternidad del campus. Cuando me preguntó si debería informar del incidente, recordé que, muchos años atrás, en mi adolescencia, yo había estado a punto de ser violada en grupo. Aunque no se lo dije a nadie en ese momento, porque no sabía qué decir o a quién contárselo, ahora sí tenía una respuesta.

La respuesta se basó en el trabajo transcultural que había empezado al comienzo de la década de 1970 sobre el contexto socio-cultural de la violación (Sanday, 1981). Este trabajo demostró que, fueran cuales fueran las bases evolutivas de la violación, la cultura marcaba la diferencia (para un tratamiento más reciente sobre el conflicto sobre las bases culturales o evolutivas de la violación, ver los artículos en Travis 2003). Revisando etnografías de 95 sociedades, encontré que la presencia de la violación estaba significativamente asociada con variables claves relacionadas con la dominación masculina, la separación sexual y una ética de la agresión masculina; por otro lado, la ausencia de violación estaba significativamente asociada con el poder femenino y las decisiones políticas tomadas por mujeres. El hallazgo de que sólo el $18 \%$ de las sociedades de la muestra podían ser etiquetadas como "propensas a violaciones", mientras que el $47 \%$ estaban, en cambio, relativamente "libres de violaciones", sugería que el contexto sociocultural de la sexualidad humana era más relevante que la biología para entender la etiología de la violación. La importancia del poder social de las mujeres en la mayoría de las sociedades libres de violación me llevó a contestar en sentido afirmativo a su pregunta sobre informar o no del caso.

Sabiendo que la comunidad de mujeres del campus la apoyaría, y que no tendría que enfrentarse a esto sola, la animé a informar del incidente, cosa que hizo finalmente. Como el caso había ocurrido en el campus, competían dos públicos. Los miembros de la fraternidad se jactaban de la fiesta, llamando a lo que había sucedido un "express", haciendo referencia al uso común del término "tren" en los campus universitarios para referirse a esta forma de sexo en grupo ["gang bang"]. Este

${ }^{3}$ Hay traducción castellana: La muerte sin llanto. Violencia y vida cotidiana en Brasil. Barcelona: Ariel. 1997. 
alarde público terminó cuando las feministas y el editor del periódico del campus censuraron lo ocurrido y lo calificaron como "violación" ["rape"]. Después descubrí que incidentes similares habían sido denunciados en campus de todo el país, y que la respuesta de las autoridades había sido inexistente o tibia en el mejor de los casos.

En Fraternity Gang Rape, difundí las problemáticas morales y sociales que estaban en juego, ofreciendo testimonios de los rituales sexuales de fraternidad que escribieron para mí participantes de diversos campus. Los resultados des-familiarizaron las explicaciones del tipo "los chicos siempre serán chicos" y "ella lo está deseando" para explicar esta forma de sexo ["gang bang"]. Los estudiantes reflexionaron sobre cómo esas categorías culturales hacen de las mujeres objetos pasivos y de los hombres agentes sexuales en rituales de dominación masculina. Comparando las descripciones gráficas de los incidentes de vinculación sexual masculina que involucraban a mujeres demasiado ebrias como para reconocer que se encontraban ante la definición legal de violación, que se refiere no sólo al poder físico sino también a la capacidad de consentimiento, intenté cambiar el conocimiento común de este tipo de conductas escribiendo principalmente para un público universitario (Sanday 2007).

El libro puede ser leído por cualquiera, incluidos los miembros de las fraternidades que han hablado de él durante años, aprobadora o desaprobadoramente. El éxito del libro - usado en muchas clases para aumentar la conciencia sobre las culturas sexuales de los campus y para cuestionar las "asunciones dadas por sentadas" sobre la acción de "pegar a las mujeres"- se manifiesta en su contribución al cambio de las definiciones populares de violación. Casi treinta años después del incidente en el que el libro está basado, puedo decir con confianza que el paradigma "lo está pidiendo" o "lo está deseando" ha sido exitosamente cuestionado, en favor de una definición clara del sexo consensuado, como opuesto a la violación, que ahora se da en muchas universidades. Cuando otro incidente similar, que llegó a los tribunales, me llamó la atención en 1990, continué con mi trabajo escribiendo un libro sobre las consecuencias legales a las que una estudiante tiene que hacer frente cuando su caso llega a juicio, examinando la historia de las demandas relacionadas con casos de violación (ver Sanday, 2011).

La muerte sin llanto. Partiendo de la tradición crítica de la escuela de Frankfurt, en su etnografía Scheper-Hughes (1992) enfatiza la importancia de trabajar con ciudadanos que actúan en interés del cambio respecto de la extrema pobreza y de la mortalidad infantil en ciertas áreas de Brasil (ver la discusión en Scheper-Hughes, 1992a, 1992b; 1995:410-412). En su debate con D'Andrade, Scheper-Hughes (1995:410) hace referencia a este trabajo de campo describiendo su transición a lo largo de los años desde "antropóloga 'objetiva' a companheira política y moralmente comprometida". Este tipo de compromiso le lleva a las estrategias de la teoría crítica: "teoría derivada en el contexto de la práctica política", reflexión, crítica cultural, y apelación a múltiples audiencias (Scheper-Hughes, 1992b:227-230).

La preocupación de Scheper-Hughes por la antropología de la violencia y la muerte puede también encontrarse en su volumen editado con Philippe Bourgois (2004) sobre la guerra y la paz, y en su trabajo (2004) sobre la venta global de 
órganos humanos. Continúa apelando a una nueva "ética del oficio", a la que se refiere como "una antropología comprometida y 'militante' basada en obligaciones éticas hacia el cuerpo y la supervivencia de nuestros informantes a través de una forma activista y comprometida de "testimonio" (1995).

Friction. Las dos siguientes obras muestran cómo la etnografía públicamente comprometida del siglo XXI tiene como objeto el cambio, en un mundo caracterizado por conexiones globales que separan al débil del fuerte por medio de las enormes disparidades en la riqueza y el expolio de la tierra y las personas. Este es un mundo en donde el etnógrafo "entra en la lucha", estudia la "fricción", y piensa en términos de "universales comprometidos" como Tsing (2005) plantea con respecto a la destrucción de la selva en Kalimantan. Los universales comprometidos de Tsing son una reminiscencia de las formulaciones macroantropológicas de Rappaport. En su etnografía, traza conexiones globales forjadas por activistas medioambientales, y desarrolla una comprensión próxima de la relación entre fricción y cambio de alcance global, mediante su experiencia de trabajo de campo en Kalimantan. No es el suyo un informe desapasionado; su pasión y su especificidad sobre el terreno sumergen al lector dentro de un complejo argumento. En sus propias palabras (2005: XII):

“...los granjeros y recolectores que conocí mejor... dieron forma a mi perspectiva. Quería contar su historia. Para hacerlo, concluí que debía poner la cuestión de la aflicción en un lugar central, y no tratar de evitarla: centrarme en el área más afligida, escribir específicamente sobre la aflicción, y usar un estilo de escritura etnográfico que dibujara sus perfiles tan vívidos como yo los conozco. Si ésta es una historia que debe ser contada, merece una escritura 'audible""

Esa escritura audible impulsa al lector, no sólo a sumergirse en los detalles de la degradación medioambiental, sino en el marco conceptual que relaciona los "encuentros a través de las diferencias" con "modelos de producción cultural" y que subraya la importancia de la fricción (un concepto multidimensional que pretende llegar más allá que el de resistencia) para "definir el movimiento, la forma cultural y la agencia" $(2005: 3,6)$.

Local Democracy Under Siege. Al otro lado del mundo, en los Estados Unidos, Holland y sus colegas dan cuenta de cómo la democracia no funciona en cinco condados de Estados Unidos situados en el estado de Carolina del Norte. Acertadamente titulada Local Democracy Under Siege [Democracia local bajo asedio] (2007), esta etnografía de equipo muestra cómo el privilegio y el neoliberalismo aplastan el llamado "Sueño Americano", y los "dramas de discordia" que tienen lugar como reacción. Siguiendo dramas de discordia como uno de sus principales métodos etnográficos, los autores examinaron "conflictos y diferencias de opinión que captaron la atención del público" (Holland et al., 2007:14). Relacionando la relevancia de la cobertura de los medios de comunicación con las tareas de la democracia local, los autores identifican la matriz de conexiones que atraviesan los ámbitos de su estudio, y concluyen que la "plutocracia, no la democracia, describe mejor el sistema político americano en todos los niveles" (2007:190). Definen la 
plutocracia "como una forma de gobierno por una élite de poder o una oligarquía formada por una clase alta de gente con riqueza y poder; no una democracia o una forma de gobierno del pueblo" (2007:188). Los autores plantean que, mientras muchos americanos parecen "mostrar un reflexivo orgullo en la democracia americana, celebrándola como un modelo para el resto del mundo", son cínicos, sin embargo, sobre la vida política, y muchos han dejado de votar y participar en ella (2007:190). Cómo el gobierno plutocrático prevalece y cómo podría cambiar son algunas de las contribuciones de esta detallada etnografía.

El grado en el que la plutocracia actualmente gobierna las elecciones en los Estados Unidos y los procesos democráticos se pone de manifiesto en las consecuencias de la decisión Citizens United del Tribunal Supremo de 2010, que equiparaba la financiación empresarial del proceso electoral con la libertad de expresión, dando así una confirmación legal al viejo dicho de que en política el dinero habla. El juez Steven discrepó con esta decisión, definiéndola como un golpe para la democracia:

\footnotetext{
"En el fondo, la opinión del Tribunal es un rechazo del sentido común del pueblo estadounidense, que ha reconocido la necesidad de evitar que las empresas socaven el autogobierno a través de la financiación, y que ha luchado contra el potencial corruptor característico de las campañas electorales corporativas desde los días de Theodore Roosevelt. Este es un momento extraño para repudiar ese sentido común. Aunque la democracia americana es imperfecta, pocos, además de la mayoría de este Tribunal, podrían haber pensado que uno de sus defectos es la escasez de dinero de las empresas en la política".
}

Aunque diferentes en el enfoque y procedentes de distintas partes del mundo, estas cuatro etnografías ofrecen un cuerpo de conceptos y procedimientos para hacer etnografía de interés público. El foco está en los "intereses públicos", sobre el supuesto de que la acción va siempre "en interés" de algunos públicos en contraste o en abierto conflicto con otros públicos o con el Estado. El marco conceptual se basa en un linaje de teóricos sociales comprometidos, cuyas investigaciones se centran en el poder de los seres humanos como agentes sociales capaces de cambiar el futuro a través de la reflexión, el compromiso social, la negociación, la construcción de consenso o la acción política. Las problemáticas teóricas se desarrollan a partir de la asunción básica de que si los humanos construyeron su mundo tienen también la capacidad de cambiarlo, incluso aunque vivan en los habitus del mundo cultural que han construido.

\section{Consolidando un marco para la etnografía de interés público}

La EIP asume tanto la continuidad como el cambio de las sociedades humanas, aunque una u otro puedan percibirse más en determinados periodos de tiempo. En el mundo de hoy, el cambio es más aparente que la continuidad, dada la evidencia de que seres humanos y grupos de todo el mundo están en disputa, adoptando, abandonando y reflexionando sobre las normas del pasado, presente y futuro en el proceso de desarrollo de nuevas posiciones y adaptaciones. La EIP une los intereses a las normas y los valores, esperanzas y sueños para el futuro, así como a las relaciones 
de producción y los sistemas de dominación. La cuestión fundamental no es cómo las poblaciones son oprimidas sino si las personas se juntan para encontrar bases comunes para resolver tensiones y problemas de calidad de vida, y en este caso, por qué y cómo lo hacen. Con respecto a esta cuestión de si la gente es, de hecho, capaz de responder, uno debe atender a las tendencias locales y globales puestas en marcha en respuesta a las hambrunas, la pobreza, los etnocidios y otros problemas.

El marco conceptual nuclear de la EIP se centra en la infinidad de caminos que encuentran los grupos humanos para resolver los problemas a los que se enfrentan, junto con el pensamiento social que guía las soluciones que pasan de generación en generación. El foco está puesto en la creatividad social humana que los grupos (públicos) despliegan para promover, reflexionar sobre, y actuar con respecto a intereses promovidos por necesidades percibidas o por una ideología compartida. La recolección de datos está basada en las diversas técnicas de análisis asociadas con la etnografía y el estudio del discurso, la cultura material y los productos de la imaginación. El objetivo principal que orienta el análisis es la descripción y el mapeado de particularidades etnográficas, de manera que las urgencias del pensamiento, el comportamiento, la acción y la producción humanos estén en primer plano. La teoría se genera a través del compromiso con los detalles de la práctica, en un estilo que hace hincapié en la resonancia con los actores con quienes uno se compromete 4 El etnógrafo no comienza asumiendo que la cultura es compartida. Como pregunta Barth (2000:147-148) en su crítica del concepto tradicional de cultura: “¿cómo podemos modelar los procesos de interacción, comunicación y constitución de significado de manera que nos den un informe plausible de la vida social tal y como se desarrolla, y nos muestren cómo estos procesos reproducen sus propias condiciones previas?"

La EIP reconoce la relación dialéctica entre el orden y el flujo en los procesos culturales. El concepto de cultura de Geertz (1973:5), que la define en términos de "redes de significado" en las que los humanos están "suspendidos" pero que ellos también hilan, sugiere flujo. El flujo se refiere al hilado y el orden al estar suspendido. Ambos están ligados a la estructura de la red, formada por campos sociales que son mantenidos y legitimados por significados culturales de carácter histórico que justifican valores y normas. La EIP identifica los momentos de elección, la resolución de conflictos y la construcción de solidaridad que producen nuevas redes de significado sosteniendo nuevas posibilidades, a veces inimaginables, para las relaciones sociales.

Barth sugiere (2002:1) que la distribución de conocimiento es un importante asunto de atención etnográfica:

"El conocimiento le da a la gente materiales para la reflexión y premisas para la acción, mientras que la "cultura" abarca con demasiada rapidez el conjunto de esas reflexiones y acciones... El conocimiento está distribuido entre la población, mientras que la cultura nos hace pensar en términos de participación difusa. Nuestro examen

${ }^{4}$ Para más información sobre lo que conlleva la empatía del "poder de la resonancia" en la práctica etnográfica, véase: Wikin, 1992. 
se aplica a las distribuciones del conocimiento - su presencia o ausencia en sujetos particulares - y los procesos que afectan esas distribuciones pueden convertirse en los objetos de estudio".

El énfasis en la especificidad del conocimiento, junto con las limitaciones que influyen en su distribución diferencial, apela a una estrategia etnográfica abierta en la que el compromiso signifique comenzar con los detalles de intereses, ideas y acciones públicamente manifestados. Esto significa comenzar por la práctica. "Dado que todos los conceptos están integrados en la práctica", dice Barth (2000:148), "su definición y su empuje pueden ser sólo determinados en el contexto de la práctica".

Poner la práctica en primer plano significa que la fase de análisis está marcada por un proceso inductivo. Los datos sobre el terreno no se enmarcan en la teoría, sino que los hechos generan conceptos que o bien se ajustan o desafían a la teoría existente. En su estudio de la democracia local, Holland et al. definen su enfoque etnográfico como uno que "descansa en la estrategia relativamente abierta de la inducción analítica", porque es "útil para, entre otras cosas, identificar nuevas y emergentes prácticas sociales y formas culturales" (2007:199). Centrándose en los "grupos activistas" y los "dramas de discordia" en su trabajo de campo en Carolina del Norte, descubrieron no sólo los grupos cívicos usuales, jerárquicamente organizados, como el PTA y el club Elks, sino también un buen número de "pequeños grupos de base" emergiendo como respuesta a las preocupaciones actuales (2007:199).

Holland et al. (2007:202-203) apuntan cómo los activistas "efectúan el cambio no sólo a través de la política electoral... sino también a través de un comportamiento conflictivo en la esfera pública", mediante el compromiso "tanto en la política cultural como en la política convencional". La política cultural es parte del flujo del compromiso social presente en muchas sociedades. Holland et al. citan el trabajo de Álvarez et al. (1998:7) que interpreta la "política cultural" como:

"el proceso que se pone en marcha cuando grupos de actores sociales conformados por, y encarnando, diferentes significados y prácticas culturales entran en conflicto... Cuando los movimientos despliegan concepciones alternativas sobre la mujer, la naturaleza, la raza, la economía, la democracia o la ciudadanía que perturban los significados culturales dominantes, ponen en marcha una política cultural".

El interés por la política cultural deriva del supuesto de que no es asumible el presunto estancamiento del orden, sino que éste está sujeto a cambios.

El enfoque básico es el estudio de los mecanismos culturales y sociales de la creatividad social humana que los grupos (públicos) despliegan para promover, reflexionar sobre, y actuar con respecto a intereses, y, de esta manera, construir vínculos de compromiso mutuo. La EIP busca esta construcción en la esfera pública, que Calhoun (2002: 248-249) ve como "un escenario para el desarrollo de solidaridad social como una cuestión de elección" allí donde "nuevas formas de imaginar la identidad, los intereses y la solidaridad posibilitan nuevas formas materiales de relaciones sociales". Cada vez más, como Tsing (2005) demuestra, la esfera pública local se une a conexiones globales. 


\section{Algunas directrices conceptuales para la etnografía de interés público}

La discusión anterior ha aludido a una letanía de términos: esfera pública, interés(es)/ público(s), dramas de discordia, y fricción. A continuación se presentan algunas directrices conceptuales generales, no como corchetes inflexibles para enmarcar el enfoque etnográfico, sino como un punto de partida para pensar en términos de investigación de interés público. El aparato conceptual se ha extraído del trabajo de teóricos críticos de todas las áreas — sociólogos, filósofos, politólogos, antropólogos- que estarían de acuerdo en que:

..."la investigación social debe combinar en lugar de separar los polos de la filosofía y las ciencias sociales: explicación y comprensión, estructura y agencia, regularidad y normatividad. Este enfoque... permite a la empresa [de la investigación] ser práctica en un sentido distintivamente moral [más que instrumental]. [El objetivo es] no solamente... proveer los medios para lograr algún objetivo independiente, sino más bien [en referencia a la reivindicación de Horkheimer] buscar "la emancipación humana" en circunstancias de dominación y opresión. Esta tarea normativa no puede llevarse a cabo sin la interacción entre filosofía y ciencia social a través de la investigación social empírica de carácter interdisciplinario" (Bohman, 2005:s/p).

La terminología extraída de estas fuentes se presenta con objeto de desarrollar una base común para el estudio interdisciplinario de la trayectoria de los intereses públicos, en un momento en que el mundo se está convirtiendo, en muchos sentidos, en una comunidad global.

a. Público(s) y contrapúblicos. El término "público" tiene una cascada de referentes sociales, que van desde discusiones meta-culturales del interés público en términos de asunciones sobre el bien público, el bienestar social, etc. -a lo que Taylor (2004) se refiere como el imaginario social-, hasta los asuntos corrientes que movilizan a la gente en torno a ciertos problemas e intereses. En un importante artículo Michael Warner (2002:49-50) distingue entre "un público" y "el público", y asocia ambos conceptos con el desarrollo de la modernidad. "El público es una especie de totalidad social", en el sentido de que "siempre que uno se dirige al público, se asume que los demás no importan". Un público, por otro lado, es menos total y más transitorio, unido momentáneamente "en una visibilidad común y una acción común". Un tercer sentido de público definido por Warner se refiere al "que se constituye sólo en relación con los textos y su circulación — como el público de este ensayo".

Delimitando los diferentes tipos de público, Warner (2002:84-85) comenta que "hay tantos matices diferentes entre los públicos como modos de expresión, estilo y espacios de circulación". Uno de estos estilos podría ser el de movilizarse específicamente contra "cualquier público general o dominante..., [en el] que los miembros se entienden no como un mero subconjunto del público, sino como constituidos a través de una relación conflictiva con el público dominante". Aquí, Warner se refiere al influyente artículo de Nancy Fraser en el que critica el concepto de esfera pública de Habermas, introduciendo el concepto de "públicos alternativos"o 
“contrapúblicos". Estos últimos están formados por "miembros de grupos sociales subordinados - mujeres, trabajadores, gente de color, gays y lesbianas" (Warner, 2002:84-85, citando a Fraser 1992:122-23).

b. Interés(es) y desinterés. En el nivel de los aspectos esenciales de la intersubjetividad y la interacción social, Bourdieu (1998b:76) dice que "los agentes sociales no participan en actos gratuitos". Los conceptos básicos que Bourdieu (1998b:85) considera "indispensables para pensar sobre la acción razonable" son habitus, campo, interés y capital simbólico. Bourdieu y Wacquant (1992:18-19) señalan que habitus y campo son conceptos "relacionales" en el sentido "de que funcionan sólo en relación uno con otro". Un campo es el "espacio de juego que existe como tal sólo en la medida en que los jugadores que entran en él, creen en y persiguen activamente los premios que ofrece". El habitus "es un mecanismo estructurador que opera desde el interior de los agentes". Es "un sistema de disposiciones duraderas y transferibles que, integrando experiencias pasadas, funciona en todo momento como una matriz de percepciones, apreciaciones y acciones, y hace posible la realización de tareas infinitamente diversificadas". En otras palabras, los habitus son las respuestas aprendidas y socializadas para participar en el juego requerido por los campos de acción.

Bourdieu define el interés en términos de "inversión" en los "juegos" de la vida. "El interés es 'estar ahí', participar, admitir que el juego merece la pena jugarlo, y que los asuntos en juego creados en y por el hecho de jugar merecen la pena; reconocer el juego y reconocer sus asuntos en juego" (1998b:77). Bourdieu opone esta concepción de interés a la de "desinterés" e indiferencia. Desinterés es una forma de inversión que se desarrolla a partir del habitus más que del cálculo racional de los riesgos que existen en un juego determinado. Por ejemplo, Bourdieu (1998b:87) se refiere a las "sociedades de honor bien constituídas" donde "la relación habituscampo es tal que, en la forma de la espontaneidad o la pasión, en la forma del 'es más fuerte que yo', se llevan a cabo actos desinteresados". Así, "se puede estar interesado en un juego (en el sentido de no ser indiferente), permaneciendo al mismo tiempo desinteresado" (Íbidem). La indiferencia, por su parte, implica no invertir en absoluto. "La persona indiferente 'no ve por qué están jugando', le es igual; está en la posición del burro de Buridan, no hace distinción". Esta persona encuentra "todo igual, no se mueve ni se ve afectada" (Íbidem). La indiferencia no implica "capital simbólico", mientras que el interés y el desinterés sí que lo hacen. Los intereses en el juego incluyen intenciones de maximizar un determinado tipo de beneficio; el desinterés disimula dichas intenciones (1998b:85-86).

Tomando un enfoque ligeramente diferente, más económico y utilitarista, Marshall Sahlins (1981) define interés haciendo referencia "al signo en acción". Con esto se refiere a que los intereses no surgen sui generis sino que están asociados como valores al sistema de signos. Estos valores son instrumentales en tanto que ayudan al actor a conseguir algo socialmente (como servir un filete mignon en vez de una hamburguesa para cenar). El actor hace uso de los signos de acuerdo a un sistema de valores convencionales, que tiene una historia como parte de una "relación in- 
tersubjetiva de signos, diferente en calidad y modo de existencia de la experiencia personal" (1981:68-9).

Mientras Bourdieu localiza el interés en el sistema constituido por campos sociales, y Sahlins localiza los intereses en los valores convencionales que constituyen el "sistema de signos", Habermas los localiza en la realidad social que denomina "acción racional comunicativa", conseguida por los seres humanos a través de la construcción de consenso (Braaten, 1991:13). De acuerdo con la discusión que hace Braaten (1991:30) del libro de Habermas Conciencia Moral y Acción Comunicativa, Habermas habla de "normas válidas" como aquellas que descansan en "fines consensualmente definidos - fines que son identificados como genuinos intereses comunes y que expresan un 'deseo común'". Habermas dice que la validez de las normas se justifica a través de la construcción de consenso. Este proceso incluye una discusión de "las consecuencias y los efectos indirectos" de normas particulares por todos los afectados (Braaten, 1991:31 citando a Habermas). La justificación implica evaluar intereses en una escala que va desde los individuales a los sociales más generales, con el fin de establecer la validez de las normas. Bajo el punto de vista de Habermas, los intereses personales no son fundamento suficiente de las reivindicaciones de validez. La reflexión sobre la validez normativa debe trascender la consideración de los intereses personales para considerar "intereses generalizables", es decir, "los intereses que un sujeto general conseguirá en una situación de consenso" (Braaten, ibid). De acuerdo con Braaten (1991:32), el "descubrimiento de intereses generalizables y aceptables es el resultado de un esfuerzo colectivo - un proceso que Habermas llama la formación discursiva de la voluntad". Este enfoque pasa por alto el estudio del flujo de la acción comunicativa subrayado por Barth. Mientras Barth se centra en el proceso, Habermas hace hincapié en el resultado consensuado.

c. Interés público y metacultura. El término "interés público" es un constructo metacultural a menudo utilizado en la política cultural de los Estados Unidos, cuando los ciudadanos o los funcionarios públicos, que están en desacuerdo o respondiendo a necesidades sociales, apoyan sus reivindicaciones basándolas "en el interés público". En los Estados Unidos, los intereses públicos son expresados de una gran variedad de formas, en los asuntos de gobierno local, estatal y nacional. A menudo, estos asuntos son expresados por los medios de comunicación. También pueden expresarse a través de pequeños grupos que se forman en determinadas comunidades para actuar en favor de intereses compartidos. Siempre que se reúnen ciudadanos para manifestar una preocupación, necesidad, demanda y llamamiento a la acción en cualquier sociedad, se puede decir que se ha formado un "público". Los intereses que motivan su asociación continuada pueden ser particulares o generales: particulares, al definir una acción concreta basada en deseos y necesidades específicos; generales, por referencia a lo que Tsing (2005:5) llama "retóricas universalizadoras de derechos y justicia", o lo que Urban podría llamar principios metaculturales. El contenido de la retórica y la naturaleza de las llamadas a la acción variarán, por supuesto, de una a otra sociedad.

Tal y como la define Urban (2001), metacultura es "la cultura sobre la cultura", esto es, la reflexión, el comentario y algunas veces la crítica cultural por la que los 
ciudadanos se refieren a su propia visión de derechos y deberes fundacionales. Con la modernización y la globalización, la retórica de los derechos implicada en los conceptos metaculturales de democracia puede convertirse en una fuente discursiva para promover protestas a nivel local. Tsing (2005) señala que la confianza en las retóricas universalizadoras de los derechos y la justicia es un modo de hacer global un caso. Su estudio sobre la fricción que motiva el movimiento medioambiental en las montañas Meratus de la selva tropical de Kalimantan, es un ejemplo del alcance desde los asuntos particulares a los que se enfrentan las poblaciones - la destrucción de huertos y de antiguos enclaves comunitarios - hasta los universales que insertan el vínculo local dentro de una cadena de conexiones globales del movimiento medioambiental (Tsing, 2005: xi, 7).

Con respecto al interés público, al que se refieren también como el "bien público" o el "bienestar común", Holland et al. (2007:237) identifican intereses opuestos. Por ejemplo, sugieren, igual que Rappaport, que al privilegiar al individuo, las fuerzas del mercado amenazan la democracia. "Uno de los supuestos cruciales de cualquier política democrática”, dicen, “es que hay un ‘bien público’ o ‘interés público’ que es superior a la suma de los intereses individuales de una población diversa". El bien o interés de orientación pública puede referirse a la salud, al medio ambiente, a los derechos básicos o a otras problemáticas. De este modo, se desarrolla en el nivel al que Urban podría referirse como campo de los principios metaculturales.

"Quienes están comprometidos con el bien público, por ejemplo, valoran el pre-
servar la calidad medioambiental para generaciones futuras, por encima de la
protección de los intereses monetarios de quienes se ocupan del beneficio en esta
generación ignorando la acumulación de daños debidos al calentamiento global.
Sin embargo, el neoliberalismo sostiene por decreto que el bienestar común no es
más que la suma de los intereses de los individuos, y argumenta además que puesto
que éste es el caso, el mercado - no el gobierno- es el principal medio, y general-
mente el único apropiado, para garantizar los derechos a aquellos individuos que lo
componen. El contra-argumento de la democracia es que el bienestar común - el
interés del grupo en cuestión, sea una comunidad o una nación- es mayor que la
suma de los intereses materiales de los individuos que forman ese colectivo, y que
este bien común sólo puede alcanzarse a través de 'las reglas de la gente', es decir,
el esfuerzo colectivo de los ciudadanos trabajando conjuntamente, no a través de la
competición entre individuos que las reglas del mercado exigen” (Holland et. al.,
2007:237).

d. Sociedad civil. En una sociedad democrática, como los Estados Unidos afirman ser a pesar de sus tendencias plutocráticas, los públicos se movilizan en la sociedad civil. La sociedad civil se define en general como la arena donde circulan las problemáticas sociales, se forman las organizaciones no gubernamentales, y las personas se juntan para alcanzar objetivos comunes. Definida de esta manera, la sociedad civil se articula con lo que Habermas llama, en referencia a la intersubjetividad del conocimiento y a la realidad social compartida, el mundo de la vida. La sociedad civil puede también definirse como un sistema social en términos de los lugares sociales situados entre el Estado y la esfera privada, pero posiblemente 
superpuestos a ambos. Es en estos lugares donde se forman los públicos, y desde donde las problemáticas sociales emergen como intereses o necesidades. En este contexto, la esfera definida por los intereses públicos no es sólo "un medio de política democrática", sino una fuerza que puede verificar los procesos políticos (ver la discusión en Taylor, 1995:208,287). De acuerdo con Taylor, la sociedad civil existe "donde la sociedad como un todo puede estructurarse a sí misma y coordinar sus acciones a través de asociaciones libres" de manera que "determine significativamente o influya en la dirección de la política estatal” (Taylor, 1995:208). Sin embargo, a la luz de la demostración de Holland et al. (2007:189-191) sobre el sofocante impacto de la plutocracia estadounidense en la acción de la comunidad local, la afirmación de Taylor parece, al menos en este caso, algo utópico. Este punto pone de relieve la necesidad de vincular los términos definidos aquí con sociedades específicas y contextos nacionales.

e. Imaginarios sociales y esfera pública. La noción de Taylor del imaginario social demuestra la inseparabilidad de públicos, intereses y debate. El imaginario social se refiere al "modo como una población determinada imagina su vida social colectiva", dándole un sentido de identidad sobre quiénes son, cómo encajaron juntos, su historia combinada, y sobre lo que pueden esperar unos de otros cuando llevan a cabo las "prácticas colectivas que son constitutivas de [su] modo de vida" (Gaonkar, 2002:10). El imaginario social es más que una idealización; es parte del orden moral que formula ideales universales ${ }^{5}$. Taylor (1994:92) afirma que el orden moral sobre el que la modernidad occidental estaba basada, se desarrolló a partir de las ideas planteadas primero por influyentes pensadores; después, estas ideas dieron forma al imaginario social de amplios sectores sociales y, finalmente, del conjunto de la sociedad. Lo mismo puede decirse sobre el movimiento global del concepto de democracia con la condición de que, mientras la idea de democracia puede moverse, las prácticas gubernamentales relativas en las democracias existentes no necesariamente siguen intactas.

Tal y como es definida por Taylor (1995:259), la esfera pública es "el espacio común en donde los miembros de la sociedad se encuentran, a través de diversos medios de comunicación (impresos, electrónicos) y también en encuentros cara a cara, para discutir asuntos de interés común; y para poder, por tanto, articular formas comunes de pensamiento respecto de esos asuntos". La idea de Habermas sobre la esfera pública se refiere a los modos en los que nuevas formas de subjetividad y formación de voluntad "surgen en y a través de la circulación de discursos de múltiples géneros", incluyendo tanto novelas, revistas y periódicos como debates públicos en diversos lugares (Gaonkar, 2002:2). La formación de públicos y la evolución de los intereses en este tipo de sociedades (de acuerdo a este punto de vista) se despliegan en la esfera pública de debate y acción. La idea es que la gente tiene el control de su destino en la medida en que tienen los medios para expresar su opinión, ya sea

${ }^{5}$ Este punto tiene cierta similitud con lo que Rappaport denomina (ver arriba) "formulaciones macroantropológicas" que unen en lugar de separar a los seres humanos; y con lo que Urban se refiere como metacultura. 
en reuniones de la comunidad, en el bar local, online, a través del voto, tuiteando o en Facebook. Aunque expresar la opinión pueda ser frustrante y parezca no tener un resultado visible, el debate y la acción en la esfera pública refuerzan al menos un sentido de agencia y autonomía.

f. La esfera del interés público y los universales comprometidos. El énfasis que Habermas pone en el discurso y el habla, sugiere que debe ponerse la atención en lo que podría llamarse la esfera del interés público. La esfera del interés público se refiere al espacio discursivo en el que los temas relacionados con el interés público circulan y se mueven. Por ejemplo, la esfera del interés público puede incluir la evaluación de los valores culturales fundamentales en tiempos de crisis y cambio. La discusión de Tsing (2005:8-10) sobre los "universales comprometidos" es útil para explorar las relaciones con el cambio. Los valores culturales fundamentales no necesariamente movilizan a la gente, aunque pueden ser parte del imaginario colectivo. Escribe Tsing: "el conocimiento que marca la diferencia a la hora de cambiar el mundo es el conocimiento que viaja y se moviliza, desplazándose y creando nuevas fuerzas y agentes históricos en su camino". Los universales comprometidos movilizan a la gente "en contextos históricos particulares que les dan contenido y fuerza". Es a través de la fricción como los universales se convierten en efectivos en la práctica.

Un ejemplo de mi experiencia sobre las violaciones de adolescentes ilustra cómo los universales comprometidos pueden movilizar a la gente a la acción en unos momentos pero no en otros de la historia. No me vi a mí misma como miembro del sexo subordinado cuando un día varios amigos me empujaron de forma amenazadora contra la pared, en un gimnasio, cuando estábamos jugando al baloncesto. No tenía ni idea de lo que planeaban, pero podía saber por sus caras que no era nada amistoso. Escapando de sus brazos, corrí sin mirar atrás. No le conté a nadie el incidente, porque no sabía qué decir o a quién contárselo. Por primera vez en mi vida (tenía catorce años) me di cuenta de que tenía que ser cuidadosa con los chicos, porque ellos no pensaban que yo mereciera respeto. En 1983, años después, cuando mi estudiante me contó lo de la violación en grupo en la fiesta de la fraternidad, me di cuenta de que la coyuntura histórica para informar estaba preparada. El movimiento anti-violación había empezado a mediados de la década de los setenta, había datos sobre la alta frecuencia de violaciones por parte de conocidos, y el movimiento feminista del campus estaba dispuesto a apoyarla. Basándome en mi investigación transcultural sobre el contexto sociocultural de la violación, que había llamado la atención en los medios de comunicación de los Estados Unidos, Europa y Australia en 1981, pude argumentar en la esfera pública del campus (en una concentración de protesta por el incidente) que la cultura, y no los genes, reforzaba la violación. Movilizando la retórica universalizadora en esta concentración puse de manifiesto también la cuestión de la igualdad sexual en el campus.

g. Poder. El poder entra en escena cuando uno se pregunta por qué algunos intereses (como los asociados con el mercado) circulan, mientras otros (como los asociados con la equidad) a menudo no lo hacen; o por qué algunos intereses son implementados en la acción social mientras que otros son cuestionados, y otros 
incluso permanecen fuera de la conciencia. La gente no se moviliza para la acción hasta que no tiene cierta conciencia sobre sus derechos, por abstracta que pueda ser, y hasta que no tiene un fuerte sentido de recompensa potencial. "A través de la fricción", señala Tsing (2005:8), "los universales pasan a ser efectivos en la práctica". La fricción permite a los universales "propagarse como marcos para la práctica del poder" (ibid:10).

El feminismo y los movimientos por los derechos civiles o por los derechos de los gays en los Estados Unidos, son un buen ejemplo de la relación entre la acción popular y el ideal de igualdad incluido en el acta fundacional metacultural de la constitución de los Estados Unidos. La larga historia de fricción que han ejercido estos movimientos - desde el tiempo de la proclamación de la emancipación hasta el presente, desde el primer encuentro en las cataratas Seneca por los derechos de las mujeres hasta los debates actuales, la historia de discursos y acciones del movimiento por los derechos gays, y el debate que enfrentó al neoliberalismo contra el "99\%" durante las campañas presidenciales de 2008 y 2012 - demuestra el estancamiento y el cambio en la fricción de las políticas culturales y sociales.

h. Multiculturalismo. En discusiones recientes, el término "multiculturalismo" se ha confundido con el antiguo término de "pluralismo cultural". En antropología (ver Sanday, 1976), este último término se refiere a las naciones en las que la esfera pública fue fragmentada en grupos hostiles o sin relación histórica, a veces con lenguas diferentes, concentrados dentro de una sola nación en un periodo post-colonial. El marco metacultural de Indonesia, que hace hincapié en la "unidad en la diversidad", es decir, en la elaboración de una conciencia nacional que rinde homenaje a la diversidad indígena histórica, es un buen ejemplo de cómo esta nación plural se construyó a partir de muchos grupos inicialmente separados. En este caso, con grupos que difieren en lengua, religión (en algunos casos), y que tienen una larga historia separada antes del periodo colonial, aquellos que continuaron viviendo en sus pequeñas aldeas se guiaron principalmente por formas culturales indígenas, incluso aunque participaran en el sistema político nacional.

En los Estados Unidos, el prejuicio que llevó a la exclusión histórica de los grupos inmigrantes definidos en términos de color, religión o nacionalidad planteó un conjunto diferente de problemas. En este caso, el término pluralismo estructural, en vez de multiculturalismo, es más apropiado. El pluralismo estructural se refiere al acceso diferencial a oportunidades y recursos, basado en signos codificados de identidad que pueden reflejar o no la diferencia cultural (ver Sanday, 1976:67-70)

El reto para la antropología será clarificar los significados asociados con el término "multiculturalismo", a la luz de una comprensión de la complejidad intra-cultural de comunidades en las que los individuos aprenden a negociar muchos mundos culturales. La etiqueta "multiculturalismo" se entiende mejor como el contexto en el que "redes de significación" grupales son intercambiadas o reconocidas y apreciadas a través de líneas sociales definidas por la raza, la clase, la etnicidad o la nacionalidad. Por ejemplo, yo puedo ser americana pero aprender a funcionar en un contexto Minangkabau, después de pasar muchos años de trabajo de campo en una aldea Minangkabau. En este sentido, como individuo, tengo tendencias multiculturales, 
que pueden incluir significados que he adquirido en muchos otros contextos socioculturales durante mi vida. La etiqueta de multiculturalismo es también apropiada cuando los grupos étnicos exhiben diferentes estructuras de red viviendo felizmente y en igualdad entre ellos.

\section{Conclusión}

El discurso del interés va desde lo particular a lo general, desde lo que motiva a los individuos a participar en la crítica cultural y a buscar un cambio a través de objetivos grupales, o por referencia a los comentarios metaculturales sobre derechos básicos y garantías constitucionales. Las instituciones operan en términos de intereses para servir algún objetivo público, como la reducción del crimen o el establecimiento de estándares para las medidas y los precios. A un nivel más general, los sistemas políticos y los movimientos sociales están caracterizados por intereses especificados en términos de garantías macro-sociales o de metas consensuadas, compartidas por la gente que se moviliza para la acción social. Los intereses están localizados también en la interpretación de necesidades, por la que un grupo define las necesidades de otro - un tema que no ha sido abordado aquí, porque requeriría una extensión más prolongada. Por ejemplo, investigadores que están en armonía con las múltiples necesidades de los pobres y de otras poblaciones que no se puede ayudar a sí mismas, para quienes organizarse no es siempre posible, han contribuido de forma importante a este tema (para un excelente estudio de las necesidades, de lo que ella llama las políticas de la interpretación de las necesidades, ver Fraser (1989:161-187)).

Los diversos niveles de análisis de datos van desde lo empíricamente fundamentado hasta lo más generalmente filosófico y abstracto, incluyendo una consideración de procesos macrosociales y metaculturales. Los problemas y procesos pueden estudiarse en cualquier lugar del mundo: desde la Australia aborigen a la América nativa. Ejemplos de esta gama de temas incluyen: 1. Tratar la creatividad social humana como un campo de acción (usando el sentido del término de Bourdieu); 2. Asentar los problemas sociales debatidos tanto en la lógica local de la diversidad cultural como en los regímenes de poder y prejuicio; 3 . Criticar los problemas sociales debatidos haciendo referencia a las definiciones metaculturales de las garantías y las expectativas macro-sociales; 4. Plantear los problemas en relación a intereses humanos generalizables que están relacionados con la calidad de vida, el bien común y el bienestar social; 5 . Examinar los problemas que movilizan a la gente para la acción; y 6. Evaluar las implicaciones del estado actual del mundo para el futuro de las especies.

El marco de la EIP es una iniciativa que examina el cambio y/o la inercia en el dominio público del debate y la acción en las esferas locales y globales. La complejidad del cambio, o la ausencia de complejidad, se refleja en las etnografías que se han considerado aquí. A pesar de las diferencias y del alcance global de los temas etnográficos citados - la cultura sexual en los campus de Estados Unidos; la pobreza, la enfermedad y la muerte en Brasil; la devastación medioambiental en la selva de Kalimantan; y la democracia local en Carolina del Norte- pueden 
observarse ciertas similitudes. Todas reflejan un compromiso ético en cuestiones de crítica social; todas está atravesadas por la pasión social de su autor; todas se centran en públicos particulares; todas exploran los intereses por los cuales la gente se moviliza para la acción; todas inspiran la reflexión sobre el cambio social; y todas se preocupan de cómo la gente encuentra un fondo común para trabajar por objetivos sociales más generales. Como tales, todas muestran el complejo funcionamiento de las limitaciones históricas y sociales de la acción humana, así como los momentos en los que la luz se abre paso y se produce el cambio.

Estos estudios son también semejantes en la comunicación con el público en general como con el académico, a través del activismo asociado con la realización de etnografía y/o con la difusión de los resultados del trabajo en la esfera pública. Los antropólogos de orientación pública, académicamente fundamentados, que se han considerado aquí apuntan al cambio, hablando a públicos amplios, a los medios de comunicación, consultando con abogados sobre temas legales, o actuando como testigos expertos además de consultando con los agentes de cambio a nivel local. Algunas de estas etnografías usan la escritura misma como el medio principal para cambiar valores y formas de ver el mundo. Al actuar así, los antropólogos cambian y crean valores fundamentales.

En un estudio de los valores fundamentales americanos, Peacock (1995:43-44) argumenta con fuerza no para que los antropólogos se unan a los políticos, filósofos, teólogos, economistas y planificadores que no tienen ningún reparo en la creación de "formulaciones normativas". "¿Por qué — pregunta — deberían los antropólogos estar fuera de este proceso?" Estoy de acuerdo, y me pregunto por qué si los religiosos se refieren a valores religiosos fundamentales, los economistas a valores de mercado, y los políticos a su visión de todos los factores que contribuyen al bien político común, entonces por qué los antropólogos no se refieren a los valores fundamentales y a los intereses que movilizan a la gente a la acción como opuestos a la indiferencia que la inmoviliza. Dada la experiencia de la antropología en la delimitación de los valores fundamentales de las redes de significado que guían la vida cotidiana, se podría esperar que los antropólogos públicamente orientados examinaran en qué medida los derechos fundamentales son vulnerados en conductas legalmente sancionadas, prácticas de mercado u oportunidades educativas.

Dicho esto, quiero plantear un desafío preguntando cómo la antropología o cualquier otra ciencia social pueden triunfar en el juego de los valores si se retiran del juego por completo. Una cosa es criticar los valores fundamentales y la apatía de las poblaciones, y otra distinta es movilizar a la gente para la acción si no se forma parte del juego, si se niega a entrar en la lucha, como diría Tsing. Formar parte del juego significa que la antropología debe ocupar su lugar en el escenario de la opinión experta y la reflexión normativa que plantea Peacock. Siguiendo a Bourdieu y recordando a Habermas, la antropología cultural académica debe aprender a jugar con las reglas del discurso de la esfera pública y debe estar preparada para hacer movimientos discursivos que atrapen la atención del público. Esto significa entrar en la esfera pública con argumentos. 
El alcance global, transcultural de la antropología, su capacidad para considerar juntos lo natural, lo médico, lo biológico, lo cultural y lo evolutivo, coloca a los antropólogos en una posición privilegiada para influir sobre los conocimientos públicos. Con la excepción de unas pocas personas muy conocidas que trabajan en temas específicos - Paul Farmer y Nancy Scheper-Hugues vienen a la mente-, la disciplina antropológica no es visible en los círculos públicos, por razones que no son del todo evidentes. Mi respuesta a este dilema es alcanzar lo común que subyace a las diferentes formas como los antropólogos examinan los problemas que nos conciernen a todos. La EIP responde a la llamada de Rappaport a trabajar en nombre del mundo y a antropologizar los conocimientos públicos. También responde al desafío de Fischer (2003) de renovar la voz etnográfica y antropológica en el siglo XXI, respondiendo a las "nuevas formas de globalización y modernización [que] están poniendo todos los lugares de la Tierra en una interacción mayor, desigual, policéntrica".

\section{Traducción: Néstor Nuño Revisión: Alvaro Pazos Garciandía}

\section{Referencias Bibliográficas}

ALVEREZ, S., E. Dagnino, and A. Escobar, eds.

1998 "Introduction: The cultural and the political in Latin American social movements." In Cultures of politics/politics of culture: Revisioning Latin American social movements. 1-32. Boulder, CO: Westview Press.

BAKER, Lee D.

1998 From Savage to Negro: Anthropology and the Construction of Race, 1896-1954. Berkeley: University of California Press.

BARTH, F.

2000 [1993] "Reflections on Theory and Practice in Cultural Anthropology: Excerpts from Three Articles," National Association for the Practice of Anthropology Bulletin. Vol. 18, No. 1, pp. 147-163.

2002 "An Anthropology of Knowledge: Sidney W. Mintz Lecture for 2000". Current Anthropology. Vol. 43, No. 1, pp. 1-18.

BENHABIB, Seyla.

1986 Critique, Norm, and Utopie. New York: Columbia University Press.

BOAS, Franz

1945 Race and Democratic Society. New York: J.J.Augustin.

BOHMAN, James

2005 Critical Theory. http://plato.stanford.edu/entries/critical-theory/

BOROFSKY, Robert

2000 “To Laugh or Cry?” Anthropology Newsletter 41(2);9-10. 
BOURDIEU, Pierre

1998a Acts of Resistance: Against the Tyranny of the Market. New York: The New Press.

1998b Practical Reason: On the Theory of Action. Stanford: Stanford University Press.

BOURDIEU, Pierre and Loic J.D. Wacquant

1992 An Invitation to Reflexive Sociology. Chicago: University of Chicago Press.

BRAATEN, Jane

1991 Habermas's Critical Theory of Society. Albany, N.Y.: State University of New York Press.

BUNZEL, Ruth

1962 "Introduction". In Anthropology and Modern Life. 4-10. By Franz Boas. New York: Norton.

CALHOUN, Craig (Ed.)

1992 Introduction. Habermas and the Public Sphere. Cambridge: MIT Press.

1995 Critical Social Theory. Oxford: Blackwell.

2002 "Imagining Solidarity: Cosmopolitansim, Constitutional Patriotism, and the Public Sphere". Public Culture 14(1):147-172.

COLE, Douglas

1983 "The Value of a Person Lies in His Herzenbildung": Franz Baffin Island LetterDiary, 1883-1884. In Observers Observed: Essays on Ethnographic Fieldwork. George W. Stocking, ed. 13-52. Madison: University of Wisconsin Press.

D'ANDRADE, Roy

1995 "Moral Models in Anthropology". Current Anthropology 36(3):399-408.

FISCHER, Michael M. J.

2003 Emergent Forms of Life and the Anthropological Voice. Duke University Press.

FORMAN, Shepard, ed.

1995 Diagnosing America: Anthropology and Public Engagement. Ann Arbor: The University of Michigan Press.

FRASER, Nancy

1989 Unruly Practices: Power, Discourse, and Gender in Contemporary Social Theory. New York: Routledge.

1992 "Rethinking the Public Sphere: A Contribution to the Critique of Actually Existing Democracy". In Habermas and the Public Sphere. Craig Calhoun, ed. 122-23. Cambridge: MIT Press.

GAONKAR, Dilip Parameshwar

2002 “Toward New Imaginaries: An Introduction". Public Culture 14(1):1-20.

GEERTZ, Clifford

1973 Interpretations of Cultures. New York: Basic Books.

1983 Local Knowledge. New York: Basic Books. 
GOLDSCHMIDT, Walter, ed.

1979 The Uses of Anthropology. American Anthropological Association, Special Publication, no. 11.

GOODMAN, Alan H., Yolanda T. Moses, Joseph L. Jones.

2012 Race: Are We So Different. Oxford: Wiley-Blackwell.

HANDLER, Richard

1998 "Raymond Williams, George Stocking, and Fin-de-siècle U.S. Anthropology". Cultural Anthropology 13(4):447-463.

HEGEL, G.W.F.

1998 "Philosophy of History: Introduction". In The Hegel Reader ed. by Stephen Houlgate, pp. 400-417. Blackwell Reader's Series: Wiley, John \& Sons, Inc.

HILL-BURNETT, Jacquetta.

1987 "Developing Anthropological Knowledge Through Application". In Applied Anthropology in America. Elizabeth Eddy and Wm. Patridge, eds. Pp. 123-139. New York: Columbia University Press.

HOLLAND, Dorothy, Donald M. Nonini, Catherine Lutz, and Lesley Bartlett

2007 Local Democracy Under Siege: Activism, Public Interests, and Private Politics. New York: NYU Press.

HYMES, Dell, ed.

1999 [1969] Reinventing Anthropology. Ann Arbor: University of Michigan Press.

LUTZ, Catherine

Homefront: A Military City and the American Twentieth Century. Boston: Beacon Press.

MORAN, Emilio F.

1996 Transforming Societies, Transforming Anthropology. Ann Arbor: University of Michigan Press.

MARCUS, George E. and Michael M.J. Fischer

1986 Anthropology as Cultural Critique: An Experimental Moment in the Human Sciences. Chicago: University of Chicago Press.

MOSES, Yolanda T.

1999 "Race, Higher Education and American Society." Journal of Anthropological Research. 55: 265-277, University of New Mexico.

ORTNER, Sherry

1984 "Theory in Anthropology Since the Sixties." Comparative Studies in Society and History 26(1):126-166.

2006 Anthropology and Social Theory: Culture, Power, and the Acting Subject. Duke University Press. 
PALEY, Julia

2001 Marketing Democracy: Power and Social Movements in Post-Dictatorship Chile. Berkeley: University of California Press.

PARKINSON, G.H.R.

1989 "Hegel, Marx and the Cunning of Reason," Philosophy, Vol. 64, No. 249 (Jul., 1989), pp. 287-302.

PEACOCK, James L.

1995 "American Cultural Values: Disorders and Challenges," In Diagnosing America: Anthropology and Public Engagement. Shepard Forman, ed. Pp. 23-50. Ann Arbor: The University of Michigan Press.

1997 “The Future of Anthropology," American Anthropologist 99(1):9-29.

1999 "Toward a Proactive Anthropology," In Transforming Academia: Challenges and Opportunities for an Engaged Anthropology. In Basch et. al. American Ethnological Society Monograph Series, No.8. pp. 21-31.

RABINOW, Paul

1983 "Humanism as Nihilism: The Bracketing of Truth and Seriousness in American Cultural Anthropology". In Social Sciences as Moral Inquiry. Norma Haan, Robert N. Bellah, Paul Rabinow, and William M. Sullivan, eds. Pp. 52-75. New York: Columbia University Press.

RAPPAPORT, Roy

1995 "Disorders of Our Own". In Diagnosing America: Anthropology and Public Engagement. Shepard Forman, ed. Pp. 235-294. Ann Arbor: The University of Michigan Press.

SAHLINS, Marshall.

1981 Historical Metaphors and Mythical Realities. Ann Arbor: the University of Michigan Press.

SANDAY, Peggy Reeves

1976 Anthropology and the Public Interest: Fieldwork and Theory. New York:Academic Press.

1981 "The Socio-cultural Context of Rape". Journal of Social Issues. 37(4):5-27.

2007 [1990] Fraternity Gang Rape: Sex, Brotherhood, and Privilege on Campus. New York: NYU Press.

2011 [1996] A Woman Scorned: Acquaintance Rape on Trial. Berkeley: University of California Press.

2003 "Rape-Free versus Rape-Prone: How Culture Makes a Difference". In Evolution, Gender and Rape. Cheryl Travis, ed. 207-22. Cambridge, Mass.: M.I.T. Press.

2012 "Public Sociocultural Anthropologies." Oxford Bibliographies Online. http:// www.oxfordbibliographies.com/view/document/obo-9780199766567/obo9780199766567-0020.xml

SANJEK, Roger

1998 The Future of Us All: Race and Neighborhood Politics in New York City. Ithaca, N.Y.: Cornell University Press. 
SCHEPER-Hughes, Nancy

1992a Death Without Weeping: The Violence of Everyday Life in Brazil. Berkeley: University of California Press.

1992b "Hungry Bodies, Medicine and the State: Toward a Critical Psychological Anthropology". In New Directions in Psychological Anthropology. Theodore Schwartz, Geoffrey M. White, and Catherine A. Lutz, eds. Pp. 221-250. Cambridge: Cambridge University Press.

1995 "The Primacy of the Ethical: Propositions for a Militant Anthropology". Current Anthropology 36(3):409-440.

2004 Parts Unknown: Undercover Ethnography of the Organs-Trafficking Underworld". Ethnography (1): 29-73

SCHEPER-Hughes, Nancy and Philippe BOURGOIS, eds.

2004 Violence in war and peace. Oxford: Blackwell Publishing.

STEVENS, Justice John Paul

2010 Opinion of Stevens, J. Supreme Court of the United States: Citizens United, Appellant v Federal Election Commission, January 21, 2010. Published on line by Legal Information Institute, Cornell University Law School. www.law.cornell.edu/ supct/html/08-205.ZX.html

STOCKING, George W.

1968 Race, Culture, and Evolution: Essays in the History of Anthropology. New York: The Free Press.

1996 Volksgeist as method and ethic : Essays on Boasian Ethnography and the German anthropological tradition. Madison: University of Wisconsin Press.

2000 "'Do Good, Young Man': Sol Tax and the World Mission of Liberal Democratic Anthropology". In Excluded Ancestors, Inventible Traditions. Richard Handler, ed 171-264. Madison: University of Wisconsin Press.

TAX, Sol

1988 "Pride and Puzzlement: A retro-introspective record of 60 Years of Anthropology". Ann. Rev. Anthropol. 17:1-21.

TAYLOR, Charles

1994 Multiculturalism and the Politics of Recognition. Princeton, N.J.: Princeton University Press.

1995 Philosophical Arguments. Cambridge, Mass. : Harvard University Press.

2002 “Modern Social Imaginaries". Public Culture 14 (1):91-124.

TOULMIN, Stephen

1982 The return to cosmology: Postmodern science and the theology of nature. Berkeley: University of California Press.

TRAVIS, Cheryl Brown, ed.

2003 Evolution, Gender, and Rape. Mass.: MIT Press.

TSING, Anna Lowenhaupt

2005 Friction: An ethnography of global connection. Princeton and Oxford: Princeton University Press. 


\section{URBAN, Greg}

2001 Metaculture: How culture moves through the world. Minneapolis: University of Minnesota Press.

WARNER, Michael

2002 "Publics and counterpublics". Public Culture 14(1):49-90.

WIKAN, Unni

1992 "Beyond the words: The power of resonance". American Ethnologist, Vol. 19, No. 3, pp. 460-482. 